This is the post print version of the article, which has been published in

Consciousness and Cognition, November 2018, Vol 51, 65-73.

https://doi.org/10.1016/j.concog.2018.10.006

This document has been downloaded from TamPub uta.fi
The Institutional Repository of University of Tampere

Eye Contact Reduces Lying

Jonne O. Hietanen, Aleksi H. Syrjämäki, Patrick K. Zilliacus, and Jari K. Hietanen Tampere University

Author Note

Jonne Hietanen, Aleksi Syrjämäki, Patrick Zilliacus, and Jari Hietanen, Human Information Processing Laboratory, Faculty of Social Sciences / Psychology, Tampere University.

Correspondence concerning this article should be addressed to Jari Hietanen, Human Information Processing Laboratory, Faculty of Social Sciences / Psychology, FI-33014 Tampere University, Tampere, Finland. E-mail: jari.hietanen@uta.fi. 


\begin{abstract}
The perception of watching eyes has been found to reduce dishonest behavior. This effect, however, has only been shown in situations where it can be explained by increased adherence to rules and norms, and thus a watching-eyes effect on dishonesty per se has not been demonstrated. Moreover, the effect has been investigated only with images of watching eyes, not in an interactive situation with a live person, which may arguably have different effects on behavior. In the present study, the effect of watching eyes on dishonesty was investigated with an interactive computer game of lying. Participants played the game against a confederate, whom they believed to be another participant. On each trial, they were briefly presented with a view of the confederate, after which they chose whether to lie in the game. The confederate alternated between the use of direct and downward gaze. The results showed that another individual's direct gaze reduced lying in the game. The findings have implications for both everyday and professional situations, such as clinical conversations and police interrogations.
\end{abstract}

Keywords: eye contact; direct gaze; watching eyes; lying; dishonesty; deception; honesty; self-awareness 


\section{Eye Contact Reduces Lying}

\section{Introduction}

The perception of another individual's direct gaze is known to influence many aspects of human emotion, cognition, and behavior (for reviews, see Conty, George, \& Hietanen, 2016; Hietanen, 2018; Kleinke, 1986; Senju \& Johnson, 2009). Among other effects, another’s direct gaze has been demonstrated to increase honest and prosocial behavior. People seem to care about others' opinion of themselves and, in situations where they are being observed by others, they behave in a more socially desirable way (Oda, Niwa, Honma, \& Hiraishi, 2011). Interestingly, even a mere image of watching eyes seems to act as a reminder of such evaluative observance and hence increase positive behavior. Studies have demonstrated eye images to increase prosocial behavior, such as helping of others (Manesi, Van Lange, \& Pollet, 2016) and giving money to charities (Powell, Roberts, \& Nettle, 2012), and reduce many forms of undesirable behaviors, ranging from minor mischief, like taking drinks without paying (Bateson, Nettle, \& Roberts, 2006), to more serious dishonesty, such as stealing bicycles (Nettle, Nott, \& Bateson, 2012).

Some researchers have explained the observed results by an increased tendency for prosocial behavior, whereas others suggest that increased adherence to norms may better explain the effects. For example, in an economic game paradigm, a robust increase in the likelihood of donating money by presenting participants with a schematic drawing of watching eyes has been repeatedly demonstrated (for a review, see Nettle et al., 2013). Importantly, however, in most of these studies, the perception of watching eyes has not been found to increase the overall amount of donations, but only the probability of donating. Nettle and colleagues (2013) explained this as a heightened awareness of norms and increased normative behavior by the perception of others’ observance, as in such economic games, 
donating something, but not excessively, is likely perceived as the norm. However, not all results fit this interpretation. In one study, for example, an eye image was found to increase non-normative generosity (charitable donations that were uncommon and not socially obligated) suggesting an increase in prosocial behavior in and of itself (Powell et al., 2012). In an inventive study, Oda, Kato, and Hiraishi (2015) examined prosocial lying and norm adherence and found watching eyes to increase norm adherence and honesty at the cost of prosocial behavior. In the experiment, participants rolled a die under a paper cup, checked the rolled number privately through a hole in the cup, multiplied the number by a certain amount of yen, and reported it on a sheet of paper. The experimenters promised to give a corresponding amount of money to charity. Therefore, in this setting, by lying and breaking the rules participants were able to give more to charity and thus act more prosocially. The results showed that, without an image of watching eyes, participants tended to lie and report the numbers as higher than was statistically expected, but in the presence of watching eyes, the numbers were reported honestly. This suggests that the primary behavioral effect of watching eyes is an increase in honesty and norm adherence, and it occurs even at the expense of prosociality. Notably though, in this study and others, which have shown a watching-eyes effect on dishonesty (Bateson et al., 2006; Nettle et al., 2012), the observed effect can be fully explained by increased norm adherence. Dishonesty, however, is not always against prevailing rules or social norms. This may be the case, for example, in telling “white lies” or in playing certain games, like poker, where bluffing is an integral part of the game. To our knowledge, no study has examined the effect in a setting where the measured form of dishonesty is not also a clear rule infringement. Therefore, a reduction in dishonesty per se by the perception of watching eyes remains to be demonstrated.

Overall, studies examining the watching-eyes effect on dishonesty are few and there is discrepancy in their results. In one study, the effect was scrutinized in three different 
experiments that each offered a possibility for economic or social gain by cheating (Cai, Huang, Wu, \& Kou, 2015). In none of the different settings did the image of watching eyes reduce the amount of cheating by participants. The authors attributed the observed null effect to the clear anonymity of the situations (the experiments were conducted in separate cubicles and all materials were anonymous), which may have reduced the salience of reputational concerns. The finding was argued to imply that an eye image does not activate one's moral standards of honesty, and it only alters behavior in situations where others' opinion of oneself may be affected. Similarly, in the studies on the watching-eyes effect on prosocial behavior and cooperation, there have been inconsistent results, with some researchers failing to find any effect (Carbon \& Hesslinger, 2011; Fehr \& Schneider, 2010). It seems that further research on the behavioral effects of watching eyes is indicated.

To our knowledge, the effect of another's gaze direction on actual lying in an interaction between two people has not been previously studied. This is rather surprising, as one’s own gaze behavior when lying to others has been extensively studied (e.g., DePaulo et al., 2003). Although the effect of perceived direct gaze on dishonest behavior has been previously investigated, as described above, lying directly to another person is in many ways different than the earlier mentioned forms of dishonesty, and we do not know if perceiving another person's direct gaze reduces lying to him or her. In direct lying, the receiving end of the dishonesty is much more salient and clearly defined compared to a vague idea of a possible sufferer. Knowing who the recipient is has been shown to reduce subsequent lying to them (Van Zant \& Kray, 2014). In an interactive situation, the recipient is also able to express doubts, which may further reduce the inclination for dishonesty. In studies on interaction media richness and deception, people have been found to lie more in a video-based interaction than in a face-to-face interaction, and even more in a text-based interaction (Rockmann \& Northcraft, 2008; Zimbler \& Feldman, 2011). An experiment that involves an 
interaction between two people also allows the use of genuine eye contact with a live person as a stimulus instead of an image of watching eyes. As described earlier, most previous studies on the effect have used eye images. Studies have shown that viewing a real person evokes different subjective and neurocognitive reactions in the perceiver than a mere image (Hietanen, Leppänen, Peltola, Linna-aho, \& Ruuhiala, 2008; Pönkänen, Alhoniemi, Leppänen, \& Hietanen, 2010; Pönkänen, Peltola, \& Hietanen, 2011). Therefore, a live person could be expected to have different, probably stronger, effects on one's subjective experience and behavior than a watching-eyes image. Another limitation of most previous studies is that they have compared a photo or a schematic picture of watching eyes to a completely different kind of image, such as a picture of flowers (e.g., Bateson et al., 2006). Despite this, the effect has been attributed to watching eyes and not the mere perception of an eye or a face stimulus, which remains a plausible interpretation of the results. Notably though, in one study that avoided this pitfall, an image of a direct gaze was found to increase prosocial behavior (helping of others) as compared to images of an averted gaze, closed eyes, or flowers (Manesi et al., 2016).

In the present study, the effect of eye contact on lying was investigated by using an interactive computer game of lying and catching another's lie. In the rules of the game, lying was acceptable and thus reduced lying could not be attributed to increased adherence to norms. Participants played the game against a confederate opponent, whom they believed to be another participant. Participants were led to believe that the study was focusing on physiological responses to the game. On each game trial, they were briefly presented with a view of the opponent through a smart glass window, after which they reported to the opponent the color of a circle appearing on the computer screen. Participants were able to lie about the color in order to earn more points in the game. The opponent alternated between the use of direct and downward gaze in a pseudorandomized order. Lying was expected to be less 
likely on trials where the opponents directed their gaze towards the participants' eyes instead of gazing downward.

After the game, participants were asked to complete self-report questionnaires. The watching-eyes effect has been attributed to an automatically-triggered feeling of being the target of another's observation, which implies heightened self-awareness (Bateson et al., 2006). Arguably, this awareness of an outer perspective on one's self could then induce favorable changes in behavior, though studies have not examined whether it mediates the effects. In accordance with the idea, however, it has been shown that another individual's direct gaze may increase public self-awareness (Myllyneva \& Hietanen, 2015; Myllyneva, Ranta, \& Hietanen, 2015) and that heightened self-awareness is associated with increased honest and prosocial behavior (Beaman, Klentz, Diener, \& Svanum, 1979; Diener \& Wallbom, 1976; Vallacher \& Solodky, 1979; van Bommel, van Prooijen, Elffers, \& Van Lange, 2012). Thus, in the present study, we also measured self-awareness with a self-report scale in both gaze conditions. Heightened public self-awareness was expected in response to another's direct gaze. The effect of watching eyes on lying was expected to be mediated by heightened public self-awareness. In addition, to examine the generalizability of lying in the game to lying in everyday life, participants completed a self-report scale of lying in the past 24 hours. A positive correlation between lying in the game and reported lying in the past day was expected. 


\section{Method}

\subsection{Participants}

Participants were 51 people aged $19-37$ years $(M=24.7$ years, $S D=4.1,26$ females, 25 males) recruited from email lists of the University of Tampere and Tampere University of Applied Sciences. This sample size exceeded Cohen’s (1992) recommendation for finding a moderate effect at .80 power $(\alpha=.05)$. The participants were all native speakers of Finnish with no reported history of neurological or psychiatric disorders. In recruitment, participants were told that they would be rewarded with a movie ticket or course credit, but if they win the game, they would be given another movie ticket. However, as the opponent in the game was not a real participant, every participant was rewarded with the extra ticket in addition to the participation reward.

Five participants were excluded from the lying data analysis. Two participants (one female, one male) were excluded due to technical problems in the experimental procedure. Two female participants were excluded for suspicion of the confederate not being another participant. One male was excluded from the analysis due to not lying at all. Additionally, one female was excluded from the Lying Frequency Questionnaire analysis due to a technical error, which occurred in the beginning of the questionnaire.

The research protocol was approved by the Ethics Committee of the Tampere region. All participants gave their written informed consent.

\subsection{Materials and procedure}

The experiment consisted of three sections: preparations, lying game, and questionnaires. The entire experiment lasted approximately one hour. Each participant arrived in the laboratory at the same time with a confederate of the same sex. Participants were led to believe that the confederate was another participant. During the whole experiment, the 
confederate behaved like another participant and the experimenter treated the participant and the confederate alike. A male experimenter welcomed the two and told them that the experiment would be carried out on computers on which an interactive game would be played. He told that the study investigates physiological reactions and for that reason two electrodes were to be connected to the fingers of one player at a time. A written consent was obtained from the participant and the confederate.

After flipping a coin, the experimenter named the participant as player number one and the confederate as player number two and guided them to seats on the opposite sides of a black panel separating the room in two. A voltage-sensitive liquid-crystal (LC) shutter window (NSG UMU Products Co., Ltd.) measuring $21.5 \mathrm{~cm} \times 38 \mathrm{~cm}$ was attached to the panel. The state of the LC window (transparent or opaque) was operated by E-Prime 2.0 software (Psychology Software Tools, Pittsburgh, PA, USA) running on a desktop computer, and at first it was set to opaque. The participant and the confederate were seated face to face on opposite sides of the LC window. They both had a 19-inch computer screen and a keyboard positioned on a table in front of them. The heights of the computer screens were such that the players were easily able to see each other over the screens when the window was transparent. Participant was seated at a distance of $70 \mathrm{~cm}$ from the computer screen and $80 \mathrm{~cm}$ from the LC window. The face of the confederate was at a distance of $70 \mathrm{~cm}$ from the LC window and $150 \mathrm{~cm}$ from the participant. After the participant and the confederate were seated, the experimenter demonstrated the function of the LC window by opening it (making it transparent) for a moment with the press of a keyboard key. Participant's and confederate's seat heights were adjusted so that they had their eyes on the same level.

The experimenter said that, in the game, player one (i.e., the participant) would be collecting points first and the physiological measurements would be taken first from him or her. He then attached two skin conductance response electrodes (Ag/AgCl) coated with 
isotonic paste to the palmar surface of the medial phalanges of the index and middle fingers on the participant's left hand. The physiological measurements were carried out only to draw participants' attention away from the actual research question, and for this reason, the skin conductance response data were not analyzed. Moreover, due to the trials having many successive and overlapping brief events (e.g., animation, sounds, and other stimuli), a reliable analysis of skin conductance responses to gaze directions or other events in the game would not have been possible.

Before the game started, the players were both shown a detailed video explaining the instructions and the scoring rules of the game and demonstrating them in game situations. Lying was explicitly allowed in the instructions (“In order to gain more points, you can at times lie about the color”). After the video, the possibility to lie was further emphasized ("If you want, you can lie that the blue circle had been red”) along with a summary of all the scoring rules (e.g., "If you report that the circle was red, you will gain 1 point" and "If the opponent checks the color and catches you in a lie, you will lose 5 points”). The experimenter verified that the players had understood the rules. He then announced that during the game he would be seated behind a curtain in a separate part of the room and not be able to observe the participants, after which he left, and the players began the game.

In the beginning of each trial of the game, the LC window turned transparent and the confederate’s face was presented against a black background for 4400 milliseconds. The confederate maintained a neutral facial expression. In half of the trials, the confederate was gazing at the participant's eyes (direct gaze), and in the other half, $20^{\circ}$ downward with a slight tilt of the head toward the computer screen on his or her side of the panel (averted gaze). In order to appear natural, on the direct gaze trials, the confederate raised his or her gaze from the computer screen toward the participant shortly (in less than one second) after the LC window had turned transparent. The direct and averted gaze trials were presented in a 
pseudorandomized order. The confederate received instructions on the gaze condition order on the computer screen on his or her side of the LC window.

The lying game was adapted from a study by Karton, Palu, Jõks, and Bachmann (2014) and run on E-Prime 2.0 software. It was presented on the computer screen in front of the participant. As said, each trial started with the presentation of a view of the confederate through the LC window for 4400 milliseconds. After 2400 milliseconds from the onset of the face stimulus, a two-second animation began on the computer screen. In the animation, pictures of a red and a blue circle alternated rapidly. The animation was presented simultaneously with the view of the confederate. Then the window turned opaque, the animation stopped, and participants were shown either a red or a blue circle on the computer screen. They were asked to report the color of the circle to the confederate by pressing left arrow (for red) or right arrow (for blue) keys on the keyboard. The confederate's response to the reported color (whether he or she wanted to see what the color had actually been) was then shown as a text "Player \#2 checks” or "Player \#2 does not check" on the computer screen. Participants gained 1 point by reporting the color to be red, no points by reporting blue, and lost 5 points if caught lying. The confederate lost 3 points if he or she checked the color and participant had reported it honestly. Participants were led to believe that the confederate made their moves in the game independently, but in actuality, the confederate's moves had been written into the computer program. See Figure 1 for an example of a trial sequence. The game consisted of 120 trials, 60 with each color. The game scores of the participant and the confederate and the trial number were presented on the right side of the computer screen.

INSERT FIGURE 1 HERE 
Participants' reports of the colors were checked 12 times (6 times in both gaze conditions), but only when they had reported the color honestly. Participants had to be checked and caught lying an equal number of times in both gaze conditions to avoid biasing them into thinking that the risk of being caught were higher after either gaze direction. They were not caught lying even once because this enabled each participant to be caught lying for the same number of times and equally in both gaze conditions without the exclusion of participants. Even a minimum limit of two lies in each gaze condition (with either of the lies being checked) could have led to the exclusion of many participants due to too few lies in either condition. Moreover, being caught (especially if it happened already on the first lies) was presumed to increase the probability of participants restraining from lying altogether, which would have been antithetical to the aim of the study.

After playing 120 trials, the game ended, and questionnaires (control questions, Situational Self-Awareness Scale, and Lying Frequency Questionnaire) followed. Participants were not yet informed that the game had finished but were led to believe that after the questionnaires, the roles in the game would switch and it would be the confederate's turn to collect points. The confederate's turn to collect points, however, was not played, as it was insignificant for the research question.

Participants were first presented with a control question: "How often do you estimate the opponent was looking at you when the window opened and you saw the opponent?” The question was answered with a number ranging from 0 to 100 percent. The aim of the control question was to exclude participants who had not noticed variation in the gaze direction of the confederate (due to, for example, avoiding looking at him or her), thus responding 0 or 100 percent.

Participants then completed the Situational Self-Awareness Scale (SSAS; Govern \& Marsch, 2001) in response to both gaze directions. The window was opened two additional 
times, and participants filled in the questionnaire after each view of the confederate. The SSAS measures three forms of situational awareness: public self-awareness (measured with items such as “Right now, I am concerned about the way I present myself”), private selfawareness (e.g., "Right now, I am conscious of my inner feelings”), and awareness of immediate surroundings (e.g., "Right now, I am keenly aware of everything in my environment”). Each of the subscales were measured with three items that were answered on a 7-point Likert scale, ranging from strong disagreement to strong agreement. The items were translated to Finnish and modified so that they referred to the moment of looking at the confederate instead of the present moment. The instructions stated that the LC window would soon open and after that, the participants would be asked how they were feeling when they were looking at the other person. They were then shown all the nine questionnaire items to familiarize with them first. A text “The window will open as soon as Player \#2 has read his or her instructions and pressed a button. Please wait.” was presented, after which the window turned transparent for four seconds and participants saw the confederate either looking at them or downward. They then completed the questionnaire regarding how they felt when the window was open. After this, participants read the same instructions again, saw the confederate now looking at the other direction and then completed the questionnaire regarding that situation. The order of the gaze directions was counterbalanced across participants.

After the SSAS, participants completed the Lying Frequency Questionnaire (Serota, Levine, \& Boster, 2010). In the instructions, participants were asked to think back to where they were and what they were doing during the past 24 hours and to count how many times they had lied in that time. They were instructed to count all lies, big and small. They were then asked separately about lies to family members, friends, business contacts, acquaintances, and total strangers. For each type of recipient, they were asked separately about lies in face- 
to-face and mediated situations (by phone or in a written message). The instructions and the questionnaire items were translated to Finnish.

Finally, participants were asked to type out their answers to two questions about suspicions regarding the study design: "What do you think is the aim of this study?" and "Do you think that something was not told about the experiment?” The aim of these questions was to assess whether participants had guessed the research question or that the opponent was not a real participant, which would have altered their perception of the game and the experiment.

After the control questions, participants were informed that the game would not continue, and the experiment was finished. They were then told about the true nature of the study and the reasons for misleading them and given the participation reward along with the extra movie ticket.

\section{Results}

\subsection{Manipulation and suspicion checks}

A manipulation check question was used to assess whether participants had noticed variation in the gaze direction. To the question "How often do you estimate the opponent was looking at you when the window opened and you saw the opponent?” participants estimated, on average, the proportion of trials with direct gaze to be $60.98 \%(S D=23.42$, range $=10$ 95). Because all participants reported having noticed that the opponent had, at times, both looked at them and away from them, no participant was excluded based on this question.

Two suspicion check questions were used to assess whether participants guessed the research question or the confederate being a research assistant. To the question of the aim of the study, no one reported the correct research question and therefore no participant was excluded. To the question of thinking that something had not been told about the experiment, 
two female participants reported having suspected that the opponent was not a real participant, and they were excluded from the analysis, as mentioned in the method section.

\subsection{Lying game}

Lying in the game was measured as the number of dishonest responses, or stated more specifically, the number of blue circles reported as red. Participants lied, on average, 22.93 times $(S D=13.51$, range $=1-50)$ on the 60 trials where a blue circle was shown. A paired samples $t$ test indicated that participants lied less on trials where the blue circle was preceded by direct gaze $(M=10.96, S D=6.94)$ than on those where it was preceded by averted gaze $(M=11.98, S D=6.98), t(45)=-2.06, p=.046, d=-0.30$. In accordance with the guidelines to reduce the risk of a type I error (Simmons, Nelson, \& Simonsohn, 2011), the statistical analyses were repeated without any data exclusions and only with the exclusions due to technical problems, and in both reruns the effect remained significant $(p=.036$ and $p=.028$, respectively).

On average, participants made 0.67 mistakes $(S D=1.56$, range $=0-6)$ of losing a point by reporting having seen blue when shown red, presumably due to lapse of attention or accidentally pressing the wrong key. The number of mistakes did not differ between the two gaze conditions, $t(45)=-0.90, p=.37, d=-0.13$.

\subsection{Situational self-awareness}

A paired samples $t$ test was conducted to compare the self-awareness ratings on the SSAS in response to direct and averted gaze (see Table 1). There was no significant difference between the gaze conditions in public self-awareness, $t(45)=1.50, p=.14, d=$ 0.22 , or in private self-awareness, $t(45)=-0.77, p=.45, d=-0.11$. However, a significant difference was found for awareness of immediate surroundings, $t(45)=-2.13, p=.039, d=$ - 
0.31. Participants reported lower awareness of surroundings in the direct gaze condition $(M=$ $4.01, S D=1.52)$ than in the averted gaze condition $(M=4.27, S D=1.41)$.

Public self-awareness was proposed to mediate the relation between eye contact and lying. However, because the predictor (gaze direction) did not have a significant effect on the hypothesized mediator (public self-awareness), mediation through public self-awareness was not possible (Baron \& Kenny, 1986).

\section{INSERT TABLE 1 HERE}

\subsection{Lying in everyday life}

In the Lying Frequency Questionnaire, participants reported having lied, on average, 2.49 times $(S D=2.98$, range $=0-12)$ during the last 24 hours. There was a trend of a positive correlation between the reported number of lies during the last day and the total number of lies in the game, $r(45)=.27, p=.079$.

\section{Discussion}

The primary aim of the present study was to investigate the effect of another individual's direct gaze on dishonesty. This was achieved by using an interactive computerassisted lying game that participants played against a confederate, whom they believed to be another participant. On each trial, participants were first briefly presented with a view of the confederate, after which they reported to the confederate the color of a circle appearing on the computer screen. Depending on the trial, the confederate was gazing either directly at the participants' eyes or downward. Participants were found to lie less on trials where the confederate gazed at the participants than on trials where he or she looked downward. There 
were 8.5 percent fewer lies on the direct gaze than the averted gaze trials corresponding to a small-to-medium effect size $(d=-0.30)$.

This is the first study to demonstrate a watching-eyes effect on dishonesty that cannot be explained by increased adherence to rules. Previous studies on this effect have shown reductions in dishonest behaviors that have been clear violations to norms and rules, such as stealing (Nettle et al., 2012) or lying to experimenters (Oda et al., 2015). Lying, however, is not always against the norms and rules, as was the case in the present study. In the present study, a reduction in dishonesty was observed in a lying game where occasional dishonesty was allowed and expected, and thus arguably normative. Furthermore, in a broader sense, most previous findings on the behavioral effects of watching eyes, such as increased prosociality, generosity, and normativity, all suggest an increase in cooperative behavior. Increased cooperation has been argued to be the primary effect of the watching eyes, having its roots in human evolution (Ernest-Jones, Nettle, \& Bateson, 2011). In this study, however, the reduction in lying in a competitive, head-to-head game can hardly be seen as increased cooperation. Therefore, instead of a mere increase in norm adherence or cooperation, the present findings demonstrate that watching eyes may reduce dishonesty in and of itself. In this sense, the results are novel and broaden the picture of the watching-eyes effects.

This study is also the first to show the effect of perceived direct gaze on dishonesty by using a live person as a stimulus and by measuring dishonesty as lying to that person in an interactive situation. Many researchers have argued for the use of truly interactive study designs in social cognition research instead of reducing social interaction to its parts and investigating these elements in isolation from each other (De Jaegher, Di Paolo, \& Gallagher, 2010; Schilbach et al., 2013). Studies on social cognition typically use passive, spectatorial setups where the other person is replaced with an image presented on a computer screen. This makes the stimulus presentation more controllable and consistent, but it leads to a situation 
where the participants are merely observers without a possibility for interaction, thus removing important social aspects of the situation. Previous studies have shown a decrease in dishonest behavior by the perception of watching-eyes images instead of a live person's gaze (Bateson et al., 2006; Nettle et al., 2012; Oda et al., 2015), and by using a completely different kind of image, such as a picture of flowers (e.g., Bateson et al., 2006), as a control stimulus. The present study expands on the previous findings by showing that the watchingeyes effect on dishonesty can be generalized to seeing another individual's direct gaze in natural social interactions, and that it is the perception of direct gaze, not that of a face or eyes, that elicits the effect.

As a secondary goal, the psychological mechanism underlying the effect was examined. We hypothesized that public self-awareness, the awareness of an outer perspective on one's self, would be heightened in response to another's direct gaze and mediate the relation between eye contact and reduced lying. Self-awareness was measured with the SSAS questionnaire (Govern \& Marsch, 2001). Unexpectedly, however, the confederate’s gaze direction was not found to affect participants' ratings of self-awareness on the scale, and, consequently, the relation between eye contact and reduced lying could not be mediated by self-evaluated public self-awareness.

The unexpected result may be explained by the use of a self-report questionnaire for the measurement of self-awareness. Self-report measures are known to be problematic because people may not want to, or not be able to, evaluate and report their own subjective states honestly and accurately (Paulhus \& Vazire, 2007). Self-report measurement of selfawareness has also lead to inconsistent findings in previous studies. Many studies have shown that another individual's direct gaze can increase self-rated public self-awareness (Hietanen et al., 2008; Myllyneva \& Hietanen, 2015; Myllyneva et al., 2015; Pönkänen et al., 2011). However, in a recent study by Hietanen and Hietanen (2017), it was not affected by 
another's direct gaze, even though in that study, eye contact was found to increase firstperson pronoun use implying heightened self-awareness. Interestingly though, in that study and in the present study, participants reported lower awareness of surroundings in response to eye contact. Awareness of surroundings is a measure of "non-self-focus" on the SSAS scale (Govern \& Marsch, 2001, p. 368), and, based on the idea of attention as a bidirectional phenomenon focused either on the self or the environment (Duval \& Wicklund, 1972), Hietanen and Hietanen (2017) proposed that the result reflects heightened self-focus. Given the above considerations, on the questions of the self-awareness effect of eye contact or the mediation of the honesty effect through self-awareness, the present results do not provide compelling evidence in one direction or another. However, the results of this study and previous studies do importantly indicate that self-report measures of self-awareness may be unreliable. Thus, further research on self-awareness and eye contact using alternative methods to self-reports is warranted.

As an increase in self-awareness was not found to mediate the effect, it is possible that some other psychological mechanism could account for it. One such explanation could be that eye contact reduces lying because of increased cognitive load, though for reasons related to the present study design, it does not seem very likely. Seeing a face with direct gaze may impair simultaneous cognitive performance (Conty, Gimmig, Belletier, George, \& Huguet, 2010; Doherty-Sneddon \& Phelps, 2005; Glenberg, Schroeder, \& Robertson, 1998), and it has been shown that increased cognitive load reduces one's abilities to lie convincingly (Vrij et al., 2008). Maintaining eye contact, too, has been shown to impair this ability. In one study, requesting participants to maintain eye contact while telling true or false stories was found to make it easier for observers to tell when they were lying (Vrij, Mann, Leal, \& Fisher, 2010). However, a careful inspection of this proposition and the present study design reveals that this is not a probable explanation for our findings. Lying is considered 
cognitively more demanding than telling the truth for several reasons. Lying requires making a decision to lie and constructing the lie (Walczyk, Roper, Seemann, \& Humphrey 2003). When lying, people also tend to monitor and adjust their behavior accordingly in order to appear honest (DePaulo \& Kirkendol, 1989), while also observing the recipient’s reaction to the lie (Schweitzer, Brodt, \& Croson, 2002). In our experiment, however, very little construction of a lie was needed, as lying consisted only of pressing one key instead of another. Moreover, as the players could only see each other at the beginning of each trial before the color of the circle was presented, participants' decision to lie was not made during eye contact, but after it. For the same reason, monitoring one’s behavior to appear honest was not needed and observing the recipient for signs of disbelief was not possible. Therefore, it seems unlikely that cognitive demands imposed by eye contact would explain the observed reduction in lying. Furthermore, because participants found out the color of the circle only after the window had been shut, they were not lying or even anticipating lying when the confederate saw them. Instead, while the window was open in the red and blue trials, they behaved identically. Therefore, the results cannot be explained by participants believing that the probability of being caught in a lie would be higher on the direct gaze trials due to the opponent seeing their intentions to lie, because of, for example, signs of restlessness or a guilty facial expression.

Another possible explanation is an increase in reputation management by the perception of another's direct gaze. As noted earlier, because lying was allowed in the game, the results could not be explained by an increased adherence to rules. Regardless of the rules, however, being caught lying is undesirable, and even shameful to most people, and therefore lying in the game did carry a certain reputational risk. Already early on in the research of watching-eyes effects, heightened concern of reputation was proposed to explain the findings (Bateson et al., 2006). This explanation is particularly powerful because, in addition to most 
results of increased prosocial and normative behavior, it can account for many of the null results of previous studies. Often in those studies, no actual reputational costs or gains could have been attained by the participants due to obvious anonymity of the situation (Cai et al., 2015; Fehr \& Schneider, 2010; Lamba \& Mace, 2010). Reputation management can also explain the results by Oda and colleagues (2015) of reduced prosocial lying because prosocial lying enabled by the study design could not have improved one’s reputation, whereas being caught lying could have damaged it. Regarding the present study, it can be argued that the result of no increase in self-rated self-awareness is against this explanation. An increase in public self-awareness can indeed be expected with reputational concerns because it refers to conscious attention toward the way one is perceived by others (Fenigstein, Scheier, \& Buss, 1975), which is largely synonymous with reputation. Reputation management (attempts to control others' impression of oneself), however, may also occur subconsciously without any attention to one's self or self-presentation (Schlenker, 1980). Therefore, an increase in reputation management by the perception of another's gaze remains a plausible, albeit speculative, explanation of the present results.

Additionally, we wanted to examine whether lying in the game was associated with lying in day-to-day life. For this purpose, a self-report questionnaire of lying in the past 24 hours was used. Participants were instructed to carefully think back over the last day and count the number of times they had lied to someone. A trend of positive correlation between lying in the game and reported lying in the past day was observed. As the same people who tend to lie more in their day-to-day life also lied more in the game, the result may indicate that there was some perceived similarity between everyday lying and lying in the game. The finding gives suggestive support for the external validity of the lying game and the use of this kind of games in the measurement of dishonest tendencies. However, as the correlation did 
not reach statistical significance, the result is only tentative and should be interpreted with caution.

One possible limitation of the present study was that participants were not caught lying even a single time. One can argue that, because of this, participants may have developed a feeling of invincibility in the game. However, this does not seem likely, because such a perception should have increased the rate of lying, and in the present study, the lying rate was actually lower than in the study that first introduced the game, where participants were occasionally also caught lying (Karton et al., 2014). Moreover, while not being caught could have aroused suspicions that the game was rigged, only two participants expressed such suspicions, and therefore the predominance of participants did not figure this out. However, as noted earlier, being caught lying is likely to induce negative, self-related emotions. It could have therefore increased the awareness of one's self and reputation and the perception of another's direct gaze as distressing or intimidating. These, in turn, could have increased the effect of another's gaze on one's behavior. Therefore, the observed effects could have been different, possibly stronger, if participants had been caught lying at least a few times during the game.

The presented results have practical implications for both everyday and professional situations. In Western cultures, people tend to look another person in the eyes when they are asking him or her something of particular importance, especially if there is a pronounced demand for an honest answer. This may be due to the common conception that avoiding eye contact is suspicious or due to heightened attentiveness to the other person (Kleinke, 1986). Be that as it may, the present results suggest that, in this kind of situations, the use of eye contact may indeed increase the probability for an honest answer. Similarly, the results have implications for professional contexts. Much of the research regarding lying and its detection has been conducted with a police interrogation context in mind (DePaulo et al., 2003). The 
present study provides further evidence for the use of eye contact in obtaining an honest answer, which may be useful information for professionals in this field. Furthermore, the practical implications extend to other professional situations that demand for, or benefit from, honesty in an interaction, such as clinical conversations, job interviews, and the like.

\section{Conclusions}

The perception of another individual's direct gaze was found to reduce subsequent lying to him or her. As far as the authors know, this is the first study to demonstrate that the perception of watching eyes reduces dishonesty in a setting where the effect cannot be explained by increased adherence to rules. The present study also showed, for the first time, the watching-eyes effect on dishonesty by having a live person with alternating gaze directions as a stimulus and by measuring dishonesty as lying to the other person in an interactive situation. No evidence of mediation of the effect through self-awareness was obtained. The findings have implications for both everyday and professional situations.

\section{Acknowledgements}

This work was supported by a grant from Alfred Kordelin Foundation to J. O. H. We thank Viivi Kervinen and Otso Lensu for their assistance with data collection and Amy Richardson for her assistance in English editing. 


\section{References}

Baron, R. M., \& Kenny, D. A. (1986). The moderator-mediator variable distinction in social psychological research: Conceptual, strategic, and statistical considerations. Journal of Personality and Social Psychology, 51, 1173-1182. doi:10.1037/0022-3514.51.6.1173

Bateson, M., Nettle, D., \& Roberts, G. (2006). Cues of being watched enhance cooperation in a real-world setting. Biology Letters, 2, 412-414. doi:10.1098/rsbl.2006.0509

Beaman, A. L., Klentz, B., Diener, E., \& Svanum, S. (1979). Self-awareness and transgression in children: Two field studies. Journal of Personality and Social Psychology, 37, 1835-1846. doi:10.1037/0022-3514.37.10.1835

Cai, W., Huang, X., Wu, S., \& Kou, Y. (2015). Dishonest behavior is not affected by an image of watching eyes. Evolution and Human Behavior, 36, 110-116.

\section{$\underline{\text { doi:10.1177/1474704915594959 }}$}

Carbon, C. C., \& Hesslinger, V. M. (2011). Bateson et al.’s (2006) cues-of-being-watched paradigm revisited. Swiss Journal of Psychology, 70, 203-210. doi:10.1024/1421$\underline{0185 / \mathrm{a} 000058}$

Cohen, J. (1992). A power primer. Psychological Bulletin, 112, 155-159. doi:10.1037/0033$\underline{2909.112 .1 .155}$

Conty, L., George, N., Hietanen, J. K. (2016). Watching eyes effects: When others meet the self. Consciousness and Cognition, 45, 184-197. doi:10.1016/j.concog.2016.08.016

Conty, L., Gimmig, D., Belletier, C., George, N., \& Huguet, P. (2010). The cost of being watched: Stroop interference increases under concomitant eye contact. Cognition, 115, 133-139. doi:10.1016/j.cognition.2009.12.005

De Jaegher, H., Di Paolo, E., \& Gallagher, S. (2010). Can social interaction constitute social cognition? Trends in Cognitive Sciences, 14, 441-447. doi:10.1016/j.tics.2010.06.009 
DePaulo, B. M., \& Kirkendol, S. E. (1989). The motivational impairment effect in the communication of deception. In J. C. Yuille (Ed.), Credibility assessment (pp. 51-70). Dordrecht, the Netherlands: Kluwer.

DePaulo, B. M., Lindsay, J. L., Malone, B. E., Muhlenbruck, L., Charlton, K., \& Cooper, H. (2003). Cues to deception. Psychological Bulletin, 129, 74-118. doi:10.1037/0033$\underline{2909.129 .1 .74}$

Diener, E., \& Wallbom, M. (1976). Effects of self-awareness on antinormative behavior. Journal of Research in Personality, 10, 107-111. doi:10.1016/0092-6566(76)90088-X

Doherty-Sneddon, G., \& Phelps, F. G. (2005). Gaze aversion: A response to cognitive or social difficulty? Memory \& Cognition, 33, 727-733. doi:10.3758/BF03195338

Duval, S., \& Wicklund, R. A. (1972). A theory of objective self-awareness. New York: Academic Press.

Ernest-Jones, M., Nettle, D., \& Bateson, M. (2011). Effects of eye images on everyday cooperative behavior: a field experiment. Evolution and Human Behavior, 32, 172178. doi:10.1016/j.evolhumbehav.2010.10.006

Fehr, E., \& Schneider, F. (2010). Eyes are on us, but nobody cares: Are eye cues relevant for strong reciprocity? Proceedings of the Royal Society of London B: Biological Sciences, 277, 1315-1323. doi:10.1098/rspb.2009.1900

Fenigstein, A., Scheier, M. F., \& Buss, A. H. (1975). Public and private self-consciousness: Assessment and theory. Journal of Consulting and Clinical Psychology, 43, 522-527, http://dx.doi.org/10.1037/h0076760.

Govern, J. M., \& Marsch, L. A. (2001). Development and validation of the situational selfawareness scale. Consciousness and Cognition, 10, 366-378.

doi:10.1006/ccog.2001.0506 
Glenberg, A. M., Schroeder, J. L., \& Robertson, D. A. (1998). Averting the gaze disengages the environment and facilitates remembering. Memory \& Cognition, 26, 651-658. $\underline{\text { doi:10.3758/BF03211385 }}$

Hietanen, J. K. (2018). Affective eye contact: An integrative review. Frontiers in Psychology, 9:1587. doi:10.3389/fpsyg.2018.01587

Hietanen, J. K., Leppänen J. M., Peltola M. J., Linna-aho K., \& Ruuhiala, H. J. (2008). Seeing direct and averted gaze activates the approach-avoidance motivational brain systems. Neuropsychologia, 46, 2423-2430.

doi:10.1016/j.neuropsychologia.2008.02.029

Hietanen, J. O., \& Hietanen, J. K. (2017). Genuine eye contact elicits self-referential processing. Consciousness and Cognition, 51, 100-115. $\underline{\text { doi:10.1016/j.concog.2017.01.019 }}$

Karton, I., Palu, A., Jõks, K., \& Bachmann, T. (2014). Deception rate in a “lying game”: Different effects of excitatory repetitive transcranial magnetic stimulation of right and left dorsolateral prefrontal cortex not found with inhibitory stimulation. Neuroscience Letters, 583, 21-25. doi:10.1016/j.neulet.2014.09.020

Kleinke, C. L. (1986). Gaze and eye contact: A research review. Psychological Bulletin, 100, 78-100. doi:10.1037/0033-2909.100.1.78

Lamba, S., \& Mace, R. (2010). People recognise when they are really anonymous in an economic game. Evolution and Human Behavior, 31, 271-278. doi:10.1016/j.evolhumbehav.2010.02.002

Manesi, Z., Van Lange, P. A., \& Pollet, T. V. (2016). Eyes wide open: Only eyes that pay attention promote prosocial behavior. Evolutionary Psychology, 14, 1-15. $\underline{\text { doi: } 10.1177 / 1474704916640780}$ 
Myllyneva, A., \& Hietanen, J. K. (2015). There is more to eye contact than meets the eye. Cognition, 134, 100-109. doi:10.1016/j.cognition.2014.09.01

Myllyneva, A., Ranta, K., \& Hietanen, J. K. (2015). Psychophysiological responses to eye contact in adolescents with social anxiety disorder. Biological Psychology, 109, 151158. doi:10.1016/j.biopsycho.2015.05.005

Nettle, D., Harper, Z., Kidson, A., Stone, R., Penton-Voak, I. S., \& Bateson, M. (2013). The watching eyes effect in the Dictator Game: It's not how much you give, it's being seen to give something. Evolution and Human Behavior, 34, 35-40.

doi:10.1016/j.evolhumbehav.2012.08.004

Nettle, D., Nott, K., \& Bateson, M. (2012). 'Cycle thieves, we are watching you’: impact of a simple signage intervention against bicycle theft. PloS ONE, 7. $\underline{\text { doi:10.1371/journal.pone.0051738 }}$

Oda, R., Kato, Y., \& Hiraishi, K. (2015). The watching-eye effect on prosocial lying. Evolutionary Psychology, 13, 1-5. doi:10.1177/1474704915594959

Oda, R., Niwa, Y., Honma, A., \& Hiraishi, K. (2011). An eye-like painting enhances the expectation of a good reputation. Evolution and Human Behavior, 32, 166-171. doi:10.1016/j.evolhumbehav.2010.11.002

Paulhus, D. L., \& Vazire, S. (2007). The self-report method. In R. W. Robins, R. C. Fraley, \& R. F. Krueger (Eds.), Handbook of research methods in personality psychology (pp. 224-239). New York: Guilford Press.

Powell, K. L., Roberts, G., \& Nettle, D. (2012). Eye images increase charitable donations: Evidence from an opportunistic field experiment in a supermarket. Ethology, 118, 1096-1101. doi:10.1111/eth.12011 
Pönkänen, L. M., Alhoniemi, A., Leppänen, J. M., \& Hietanen, J. K. (2010). Does it make a difference if I have an eye contact with you or with your picture? An ERP study. Social Cognitive and Affective Neuroscience, 6, 486-494. doi:10.1093/scan/nsq068

Pönkänen, L. M., Peltola, M. J., \& Hietanen, J. K. (2011). The observer observed: Frontal EEG asymmetry and autonomic responses differentiate between another person's direct and averted gaze when the face is seen live. International Journal of Psychophysiology, 82, 180-187. doi:10.1016/j.ijpsycho.2011.08.006

Rockmann, K. W., \& Northcraft, G. B. (2008). To be or not to be trusted: The influence of media richness on defection and deception. Organizational Behavior and Human Decision Processes, 107, 106-122. doi:10.1016/j.obhdp.2008.02.002

Schilbach, L., Timmermans, B., Reddy, V., Costall, A., Bente, G., Schlicht, T., \& Vogeley, K (2013). Toward a second-person neuroscience. Behavioral and Brain Sciences, 36, 393-414. doi:10.1017/S0140525X12000660

Schlenker, B. R. (1980). Impression management: The self-concept, social identity, and interpersonal relations. Belmont, CA: Wadsworth.

Schweitzer, M. E., Brodt, S. E., \& Croson, R. T. (2002). Seeing and believing: Visual access and the strategic use of deception. International Journal of Conflict Management, 13, 258-375, https://doi.org/10.1108/eb022876.

Senju, A., \& Johnson, M. H. (2009). The eye contact effect: Mechanisms and development. Trends in Cognitive Sciences, 13, 127-134. doi:10.1016/j.tics.2008.11.009

Serota, K. B., Levine, T. R., \& Boster, F. J. (2010). The prevalence of lying in America: Three studies of self-reported lies. Human Communication Research, 36, 2-25. doi:10.1111/j.1468-2958.2009.01366.x 
Simmons, J. P., Nelson, L. D., \& Simonsohn, U. (2011). False-positive psychology: Undisclosed flexibility in data collection and analysis allows presenting anything as significant. Psychological Science, 22, 1359-1366. doi:10.1177/0956797611417632

Vallacher, R. R., \& Solodky, M. (1979). Objective self-awareness, standards of evaluation, and moral behavior. Journal of Experimental Social Psychology, 15, 254-262.

\section{doi:10.1016/0022-1031(79)90036-2}

van Bommel, M., van Prooijen, J. W., Elffers, H., \& Van Lange, P. A. (2012). Be aware to care: Public self-awareness leads to a reversal of the bystander effect. Journal of Experimental Social Psychology, 48, 926-930. doi:10.1016/j.jesp.2012.02.011

Van Zant, A. B., \& Kray, L. J. (2014). “I can't lie to your face”: Minimal face-to-face interaction promotes honesty. Journal of Experimental Social Psychology, 55, 234238. doi:10.1016/j.jesp.2014.07.014

Vrij, A., Mann, S., Leal, S., \& Fisher, R. (2010). 'Look into my eyes’: Can an instruction to maintain eye contact facilitate lie detection? Psychology, Crime \& Law, 16, 327-348. doi: $10.1080 / 10683160902740633$

Vrij, A., Mann, S. A., Fisher, R. P., Leal, S., Milne, R., \& Bull, R. (2008). Increasing cognitive load to facilitate lie detection: The benefit of recalling an event in reverse order. Law and Human Behavior, 32, 253-265. doi:10.1007/s10979-007-9103-y

Walczyk, J. J., Roper, K. S., Seemann, E., \& Humphrey, A. M. (2003). Cognitive mechanisms underlying lying to questions: Response time as a cue to deception. Applied Cognitive Psychology, 17, 755-774. doi:10.1002/acp.914

Zimbler, M., \& Feldman, R. S. (2011). Liar, liar, hard drive on fire: How media context affects lying behavior. Journal of Applied Social Psychology, 41, 2492-2507. doi:10.1111/j.1559-1816.2011.00827.x 
Figure captions

Figure 1. An example of a trial sequence. The participant first saw the confederate opponent through the transparent LC window. Then, the window turned opaque and the participant was presented with a red or a blue circle. The participant decided which color to report to the opponent, who then decided whether he or she believed it. Finally, the scores were updated based on the decision of the opponent. 
Tables

Table 1

SSAS Ratings by Gaze Direction

\begin{tabular}{|c|c|c|c|c|c|c|c|c|}
\hline \multirow[b]{2}{*}{ Subscale } & \multicolumn{2}{|c|}{ Direct } & \multicolumn{2}{|c|}{ Averted } & \multirow[b]{2}{*}{$t(45)$} & \multirow[b]{2}{*}{$p$} & \multirow[b]{2}{*}{$95 \%$ CI } & \multirow[b]{2}{*}{ Cohen's $d$} \\
\hline & $M$ & $S D$ & $M$ & $S D$ & & & & \\
\hline Public & 3.21 & 1.51 & 2.93 & 1.51 & 1.50 & .14 & {$[-0.10,0.66]$} & 0.22 \\
\hline Private & 4.29 & 1.31 & 4.37 & 1.16 & -0.77 & .45 & {$[-0.29,0.13]$} & -0.11 \\
\hline Surroundings & 4.01 & 1.52 & 4.27 & 1.41 & -2.13 & .039 & {$[-0.51,-0.01]$} & -0.31 \\
\hline
\end{tabular}

Note. CI = confidence interval. 